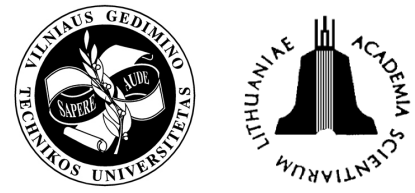

\title{
ANALYSIS OF EMERGENCY BRAKING OF A VEHICLE
}

\author{
Nerijus Kudarauskas \\ Dept of Automobile Transport, Vilnius Gediminas Technical Universitety \\ J. Basanavičiaus g. 28, LT-03224 Vilnius, Lithuania.E-mail: tiauto@ti.vgtu.lt
}

Received 24 January 2007; accepted 2 May 2007

\begin{abstract}
In this paper, braking of cars is analyzed: the analytic formulas for description of the said process and the diagrams for its illustration are provided, its mode of operation when the wheels of the car are not blocked is discussed upon, the most important factors that impact it are described herein. The key indicators of braking (such as the settled deceleration, the braking distance, etc.) are discussed upon and their values corrected in experimental way are provided. Their graphical responses and numerical values recommended for calculations bound up with technical experts' examination of traffic accidents as well as more specifically defined methodologies for them are provided.
\end{abstract}

Keywords: vehicle, ABS, braking, dynamics, experimental research.

\section{Introduction}

Vehicle braking is a complicated process. It is predetermined by various factors that differ in their character of impact, intensity and duration. The dynamics of braking describes the ability of the vehicle to reduce its speed immediately. Effective braking system provides the driver a possibility of reliable control of the vehicle at high speed and, if required, its stopping in short distance.

Modern vehicles are provided with service brakes, reserve brakes, parking brakes and auxiliary brakes. In cars, the parking brake is used as a reserve brake and the engine is used as an auxiliary brake. The system of service brakes (foot brakes) is the most important in respect of control and safety of a vehicle.

One of the principal braking parameters of a vehicle is the settled longitudinal deceleration $a_{\mathrm{x}}$. If cohesion of tyres of all wheels with the road coating is fully used, it may be theoretically calculated according to the following formula:

$$
a_{x n}=\varphi_{x} \cdot g,
$$

where: $\varphi_{x}$ - the coefficient of longitudinal cohesion of tyres with the road coating (hereinafter referred to as "the coefficient of cohesion"); $g$ - acceleration due to gravity $\left(g=9.8 \mathrm{~m} / \mathrm{s}^{2}\right)$.

The values of the deceleration of braking in equation (1) calculated according to the formula depend on the physical features of the wheel and road friction (it is the ideal value for braking). Since a vehicle is not perfect in technical respect, the efficiency of braking is some less. The European Union Directive 71/320 [1] provides that this criterion should satisfy the following condition:

$$
a_{x n} \geq\left[0.1+0.85\left(\varphi_{x \max }-0.2\right)\right] \cdot g .
$$

In reference books for experts' examination of traffic accidents as well as in scientific references on dynamics of vehicles, the provided value of cohesion of tyres with dry asphalt is $\varphi_{x}=0.8$. After inserting this value into the equations (1) and (2), we find the deceleration of a vehicle in good technical condition while its braking on dry asphalt makes $a_{\mathrm{x}}=6.0-7.85 \mathrm{~m} / \mathrm{s}^{2}$. The value of the coefficient of cohesion equal to 0.8 may be applicable only to old cars and tyres produced about the year 1980. For the present-day cars, the maximum coefficient of cohesion is $\varphi_{x}=1.0-1.2$, if braking takes place on dry asphalt [2]. Because of this, the deceleration of old cars with modern tyres may reach $7.35-9.3 \mathrm{~m} / \mathrm{s}^{2}$.

The majority of modern vehicles are equipped with anti-lock brake system (ABS), and their real braking distance is very much alike as the theoretically calculated one upon the maximum values of the coefficient of cohesion. So, the deceleration of such vehicles may be close to $g=9.8 \mathrm{~m} / \mathrm{s}^{2}$.

\section{Anti-lock brake system (ABS)}

The anti-lock brake system is required to avoid wheel locking during braking, i.e. to ensure distribution of braking forces between the wheels according to the conditions of their cohesion with the supporting surface.

On emergency braking or braking by an operational mode on the iced road, all wheels of the vehicle or some 
of them can be locked. ABS allows avoiding this. It distinguished itself for the following advantages [3]:

- the vehicle remains under control, although the braking and side forces increase;

- the minimum braking distance is ensured (a good controllability and stability allow to reduce the braking distance);

- wear of tyres is reduced.

The following requirements are set for ABS:

- ABS should operate, when the driving speed is very low;

- ABS should respond to the conditions of cohesion with the road;

- a possibility of control on turns should be ensured;

- ABS should recognize aquagliding and respond to it;

- a possibility of braking by the engine should be provided;

- if an error predetermining ABS functions is detected, the principal braking equipment should further operate without trouble. A control indicator shall warn about a fault of ABS.

The diagram of variation of the speed of a vehicle with ABS on its braking is shown in Fig 1 [4]. When the brake pedal is pressed, the value of the rotational speed of the wheels decreases by a certain value dependently on the speed of the vehicle (the point 1). When the pressing force onto the brake is larger or the road is slippery, the rotational speed of one or several wheels reduces considerably (the point 2).

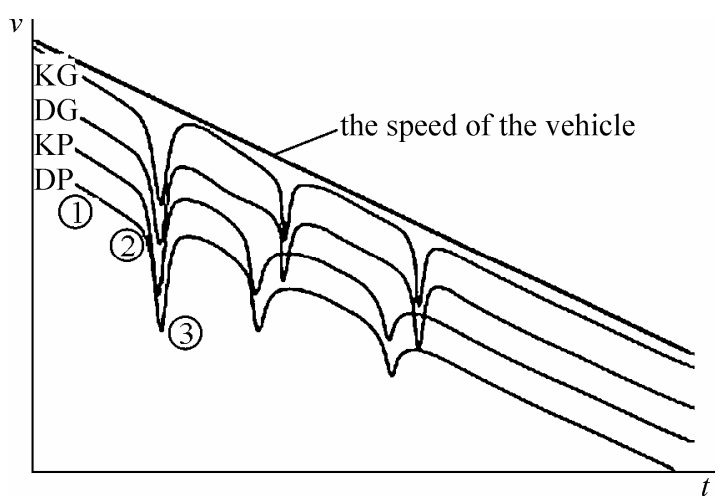

Fig 1. Diagram of variation of the speed of a vehicle with ABS on its braking

It means that the value of the coefficient of cohesion of the tyres with the surface of the road passed through the peak of the curve $\varphi_{x}(t)$ shown in Fig 2, and their locking started. At that time, ABS is activated and it releases the brakes (the point 3 ). When the speed of the wheels increases again, the brakes are activated again.

The above-described process is further repeated until the vehicle is braked to the desired speed. The purpose of ABS is keeping the maximum value of cohesion of tyres with the surface of the road (see Fig 2).

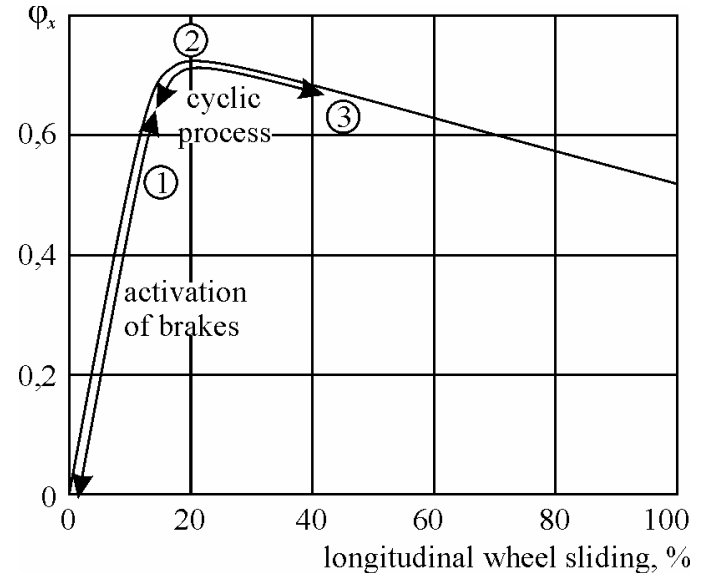

Fig 2. The response of the coefficient of cohesion of tyres with the surface of the road

\section{Vehicle braking without locking its wheels}

In absence of a braking-force regulator and antilock system (ABS), the total braking force is distributed between axles of the vehicle according to the set proportion, not to the vertical loads. Because of this, the wheels of the front axle and rear axle are not locked simultaneously. If tyres are cohered well with the surface of the road, usually the rear wheels are locked first. If values of $\varphi_{x}$ are low, both front wheels and rear wheels can be locked first.

If the rear wheels are locked, the vehicle loses its transversal stability and if the front wheels are locked, the control worsens.

Designing and manufacturing should ensure straight-line movement of the vehicle on its emergency braking, i.e. the larger relative braking forces of the wheels of front axle, as compared to the relative braking forces of the wheels of the rear axle, should be ensured. The latter requirement was provided in the European Union Directive 71/320.

The coefficient of distribution of braking forces $\beta_{T}$ is the ratio of the braking force that impacts the wheels of front axle with the total braking force of both axles [5]:

$$
\beta_{T}=P_{s t 1}\left(P_{s t 1}+P_{s t 2}\right),
$$

where $P_{s t 1}$ and $P_{s t 2}$ - the braking forces that impact the wheels of the front axle and the rear axle, respectively.

The forces $P_{s t 1}$ and $P_{s t 2}$ depend on the structure of the braking system. So, the coefficient $\beta_{T}$ can be calculated for any vehicle according to the known parameters of the braking system (see Fig 3).

If we neglect the energy losses to overcome resistance forces, the maximum braking acceleration of a vehicle at the limit of locking of the rear wheels (still keeping stability) will be:

$$
a_{x}=\frac{l_{1} \cdot \varphi_{x} \cdot g}{L\left(1-\beta_{T}\right)+h_{c} \cdot \varphi_{x}},
$$

where $L$ - the wheel base, $h_{c}$ - the height of the center of gravity from the surface of the road; $l_{1}-$ the distance 


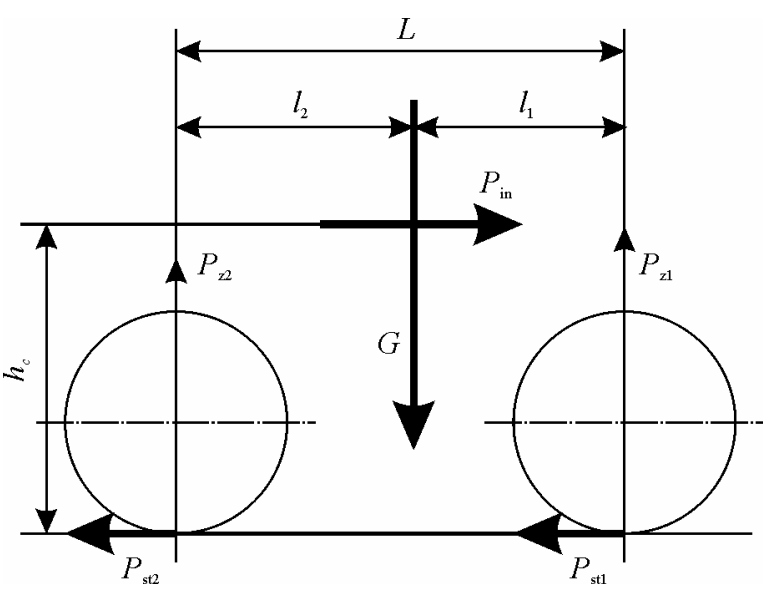

Fig 3. The forces that impact a vehicle on its braking

between the reaction vector of the front wheel and the gravity force vector.

The maximum braking acceleration of a vehicle at the limit of locking of the front wheels is as follows:

$$
a_{x}=\frac{l_{2} \cdot \varphi_{x} \cdot g}{L \cdot \beta_{T}-h_{c} \cdot \varphi_{x}},
$$

where $l_{2}$ - the distance between the reaction vector of the rear wheel and the gravity force vector.

Seeking to establish which of the above-provided formulas should be used, first of all, the value of the coefficient of cohesion $\varphi_{o p t}$, that conforms to the situation when wheels of both axles are locked simultaneously should be found:

$$
\varphi_{\text {opt }}=\left(L \cdot \beta_{T}-l_{2}\right) / h_{c} .
$$

If the real value of the coefficient of cohesion exceeds $\varphi_{\text {opt }}$, the rear wheels will be locked first on braking the vehicle and the formula (4) will be used for calculating the braking acceleration. If the real value of the coefficient of cohesion is less than its optimum value $\varphi_{\text {opt }}$, the front wheels will be locked first on braking the vehicle and the formula (5) will be used for calculating the braking acceleration. If the value of $\varphi_{\text {opt }}$, is close to 0 or negative, only rear wheels will be locked upon any conditions of movement.

The braking distance of a vehicle with unlocked wheels shall be calculated according to the following formula:

$$
S_{0}=\left(t_{1}+t_{2}+0,5 \cdot t_{3}\right) \cdot v_{0}+v_{0}^{2} /\left(2 a_{x}\right),
$$

where the relevant values of deceleration should be inserted. If the initial speed of the vehicle is not known, the braking distance of a vehicle with unlocked wheels usually (as distinct from the length of the sliding trace of locked wheels) can be found with a considerable error only and this circumstance can predetermine the reliability of the results obtained.

Although experts use experimental coefficients (where accuracy of their choosing depends on the qualification of the experts) for calculating the speed $v_{0}$ according to the length of the sliding trace, the results obtained are sufficiently close to the real values in the majority of cases. In absence of sliding traces, the experimental calculations are carried out using indefinite data and the accuracy of results becomes lower.

The value of the speed calculated for such a case is mostly acceptable. If the wheels of the vehicle were not sliding on braking, the vehicle can be stopped in the same distance upon a lower speed and intensity of braking.

On emergency braking, the braking forces of the vehicle's wheels should not exceed the forces of cohesion of the tyres with the road. So, the calculated value of deceleration for a vehicle with locked wheels will be less and the time and distance will be larger as compared to a case when the coefficient of cohesion is fully used (for example, in vehicles equipped with ABS).

\section{The comparison of the braking processes in vehicles with and without $A B S$}

In vehicles without anti-lock braking system, the acceleration of braking is decreasing on an increase of the driving speed, while in vehicles with ABS, it increases when the driving speed is under $100-120 \mathrm{~km} / \mathrm{h}$ and decreases on a further increase of the speed.

As it is known from the theory of vehicles, the deceleration of a vehicle in good technical condition without $A B S$ reaches its peak in the braking diagram at the very beginning of the braking process and then some decrease of it takes place [6]. It is caused by the fact that the peak of the deceleration is reached before locking the wheels of the vehicle. After their locking, some decrease of the braking acceleration takes place, because, as it is known, braking of a locked wheel is less efficient (see Fig 4, b).

Thus, the deceleration peak lasts a larger part of the whole braking of a vehicle without ABS at lower driving speeds; at higher driving speeds, when braking is longer, the deceleration peak lasts a smaller part of the braking. This circumstance explains decreasing of the deceleration of vehicles without ABS on increase of the initial driving speed.

On braking a vehicle with ABS, the wheels are not locked within the whole process of braking, no peak of the deceleration appears at the beginning of the braking. Even on the contrary, on braking vehicles with ABS, when an "adjustment" of the interaction between the wheels and the surface of the road takes place, the phase of increase of the deceleration is followed (on further braking) by some additional increase, thus some lower values of the deceleration are found at the beginning of braking and the maximum values are usually found in the steady phase of braking and at its end. This fact explains an increase of the deceleration while increasing the initial speed of a vehicle with ABS (see Fig 4, a).

If wheels of a vehicle on its braking are not locked, it is impossible to establish the efficiency of its braking without experimental research (when no equipment for registering the braking parameters is provided in the vehicle), because the braking force 

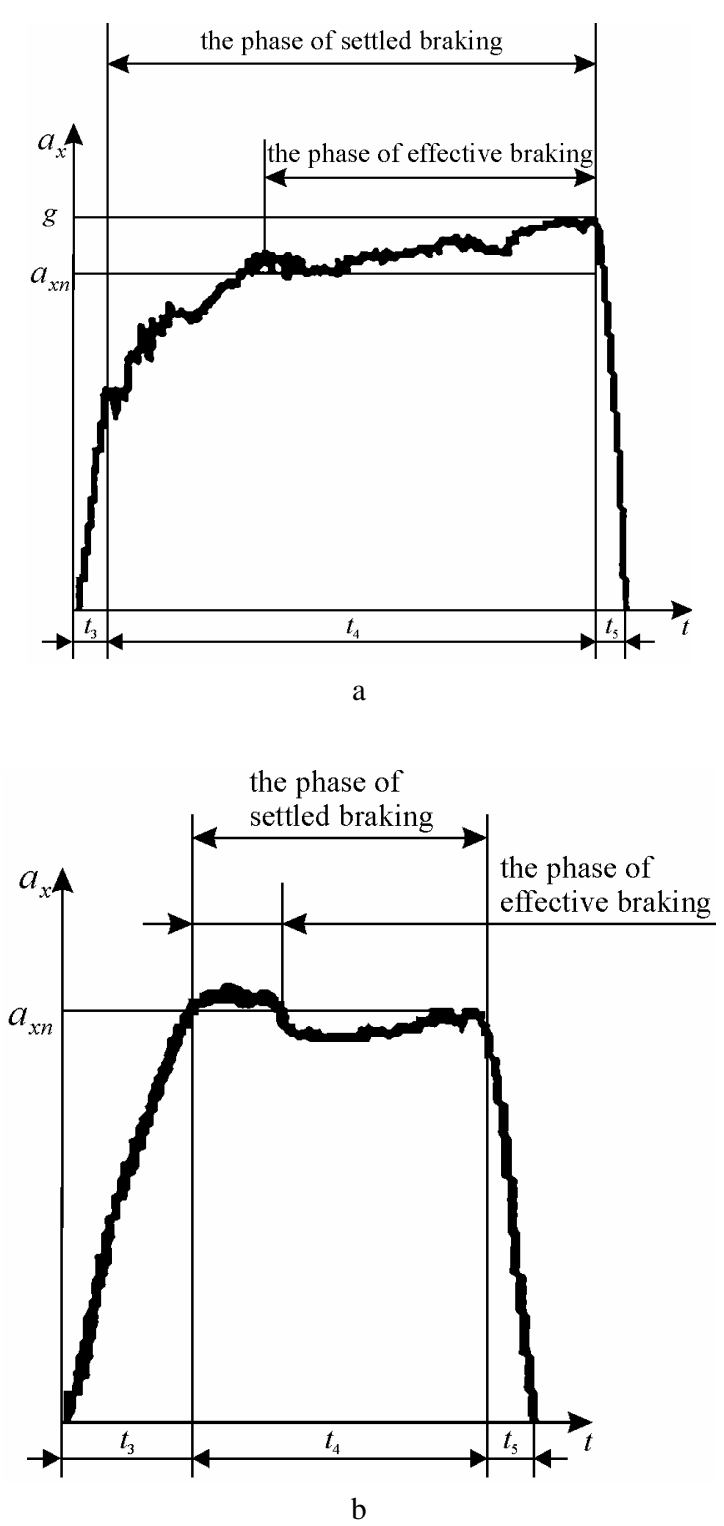

Fig 4. The braking diagrams: a - for a vehicle with ABS; $\mathrm{b}$ - for a vehicle without ABS

could be restricted by the structure of the brakes and predetermined by the technical condition.

The deceleration of a vehicle upon specific road conditions can be found with a higher accuracy, if an experimental research is carried out. The deceleration can be measured using a special device (decelerometer) or may be calculated according to the following formula, if the initial driving speed of the vehicle and the length of the braking trace are known:

$$
a_{x n}=\frac{v_{0}^{2}}{26 \cdot S_{4}+3,6 \cdot v_{0} \cdot t_{3}} .
$$

\section{Experimental research on vehicle braking. The principal graphical responses}

The goal of the experimental research is establishing the driving parameters of cars on their emergency braking - the settled longitudinal deceleration $a_{x n}$, the time $t_{3}$ of increase of the deceleration, the duration $t_{4}$ of the settled deceleration, the time $t_{5}$ of moving with released brakes and other parameters upon the fixed values of the duration of braking $t$. The data of experiments and theoretical calculations are needed for carrying out experts' examinations of traffic accidents or assessing the actions of participants of traffic in a specific case [7].

For the experiments, 10 cars in good technical condition were chosen; they were exploited for 12 years on the average (manufactured in the years 1987-2001).

The tests were carried out on dry horizontal and even (in this case, the microroughness was not taken into account) non-roughened asphalt concrete road coating. Two cars were equipped with anti-lock braking systems (ABS). All cars under investigation were with summer tyres.

In the experiments, a device for measuring the deceleration of vehicles (decelerometer) MAHA VZM 100 was used; the device is fit for such measuring both in vehicles with hydraulic and pneumatic braking system as well as vehicles with ABS.

Conformity of the measuring device VZM 100 to the standards set for control devices was approved and certified by German Association for Technical Inspection (TUV). This device is used at Lithuanian centers of technical inspection for establishing the efficiency of vehicle braking on the basis of the maximum deceleration.

On the basis of dependence of the deceleration $a_{x}$ on time, we can calculate the changes of the driving speed $v$ and the distance $S$ for any specified moment $t$ of braking.

On the basis of the found parameters of the vehicle's movement, we can provide the regularities of variation of the maximum values of deceleration for specific cases (see Fig 5).

The diagrams below were formed on the basis of the data of the experiments.

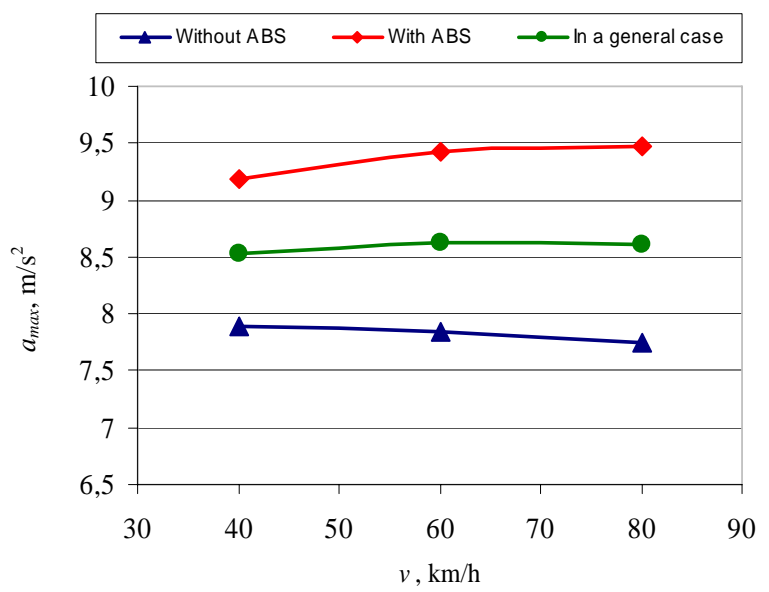

Fig 5. The dependence of the maximum deceleration on the initial speed of movement of the vehicle 


\section{The analysis of the results of the experimental research}

After completion of the experimental research on emergency braking of cars, it is important to compare their data to the results of calculation of individual parameters of movement.

It may be seen from the dependence shown in Fig 5 that a higher maximum value of the deceleration is reached on increasing the initial speed of movement of a vehicle with ABS. On the contrary, the deceleration decreases on increasing the initial speed of movement of a vehicle without ABS. So, the statements of the paragraph 3 were confirmed.

The dependence of the settled deceleration $a_{\mathrm{xn}}$ on the initial speed of movement conforms to similar regularities (see Fig 6). According to the data of experiments, when the speed before emergency braking is $40 \mathrm{~km} / \mathrm{h}$, the settled deceleration of vehicles with ABS is higher, as compared to the one of vehicles without ABS, by about $13 \%$, and if the speed is $80 \mathrm{~km} / \mathrm{h}$ by about $31.5 \%$.

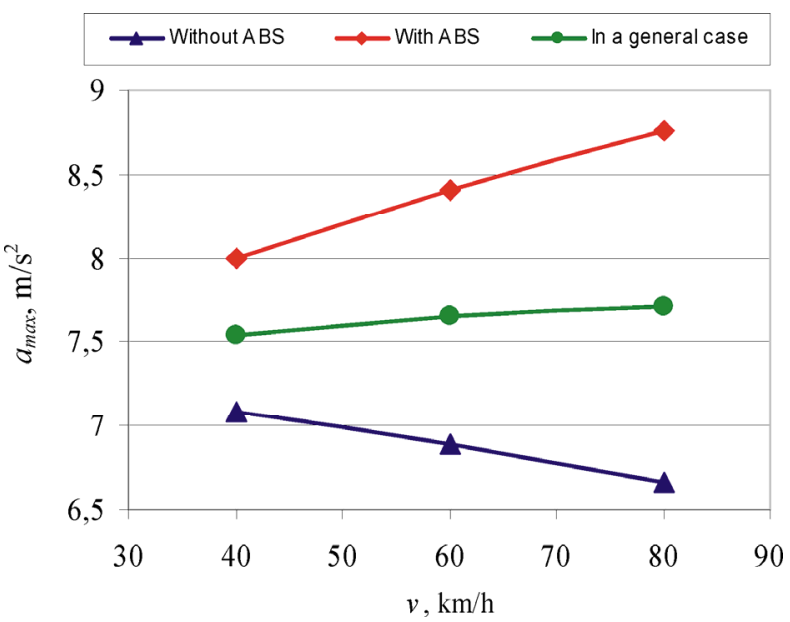

Fig 6. The dependence of the settled deceleration on the initial speed of movement of the vehicle

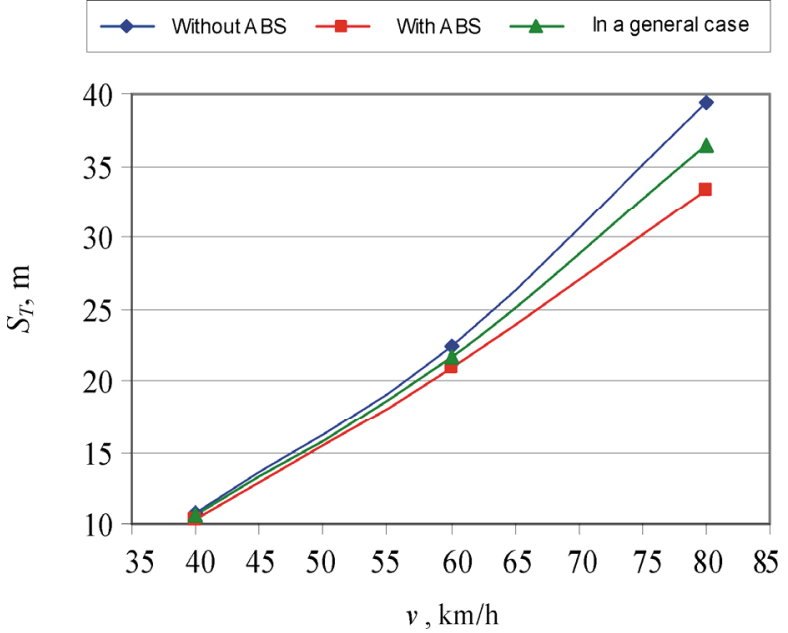

Fig 7. The dependence of braking distance on the initial speed of movement of the vehicle
It was found in the experimental research that a positive impact of anti-lock braking system (ABS) upon the braking distance of a vehicle on dry asphalt concrete road coating expresses itself on increase of the initial speed (see Fig 7): if the initial speed of a vehicle with ABS is $40 \mathrm{~km} / \mathrm{h}$, its braking distance reduces to $\approx 0.46 \mathrm{~m}$ $(4.26 \%)$ on the average, if the speed is $60 \mathrm{~km} / \mathrm{h}-$ to $\approx 1.57 \mathrm{~m}(6.87 \%)$, and if the speed is $80 \mathrm{~km} / \mathrm{h}$ - the braking distance reduces to $\approx 6.15 \mathrm{~m}(15.59 \%)$.

If the initial speed is equal to 40,60 and $80 \mathrm{~km} / \mathrm{h}$, respectively, the maximum values of ST differ from the average values by 19,13 and $19 \%$, respectively, and minimum values of $S_{\mathrm{T}}$ differ from the average values by 15,11 and $10 \%$, respectively.

\section{Conclusions and proposals}

Vehicle braking is a complex process predetermined by many factors that may be casual ones, such as the parameters of the structure of the vehicle and the ones of the road coating as well as mental and physiological peculiarities of the driver, so the maximum possible number of them should be assessed in order to describe braking in detail. The braking distance is mostly impacted by the following factors: the speed $v_{0}$ of movement before braking, the time $t_{1}$ of response of the driver, the time $t_{2}$ of delay of the drive of the brakes, the time $t_{3}$ of increase of the deceleration, the time of $t_{4}$ variation of the settled deceleration, time $t_{5}$ of moving with released brakes, and the settled deceleration $a_{\mathrm{xn}}$.

After discussing upon the peculiarities of vehicle braking, assessing the parameters of the process and completing the experimental research on the latter, the following conclusions can be made:

1. On the experiments, the settled deceleration $a_{x n}$ of vehicles with ABS varied from $8.00 \mathrm{~m} / \mathrm{s}^{2}$ (when the speed was $40 \mathrm{~km} / \mathrm{h}$ ), then $8.41 \mathrm{~m} / \mathrm{s}^{2}$ (upon $60 \mathrm{~km} / \mathrm{h}$ ) up to $8.76 \mathrm{~m} / \mathrm{s}^{2}$ (upon $80 \mathrm{~km} / \mathrm{h}$ ), and the maximum values often were over $9 \mathrm{~m} / \mathrm{s}^{2}$. In vehicles without ABS, $a_{x n}$ varied from $7.00 \mathrm{~m} / \mathrm{s}^{2}$ (upon $40 \mathrm{~km} / \mathrm{h}$ ), $6.89 \mathrm{~m} / \mathrm{s}^{2}$ (upon $60 \mathrm{~km} / \mathrm{h}$ ) up to $6.66 \mathrm{~m} / \mathrm{s}^{2}$ (upon $80 \mathrm{~km} / \mathrm{h}$ ), and the maximum values often were up to $8.3 \mathrm{~m} / \mathrm{s}^{2}$. On increase of $v_{0}$, the difference of $a_{x n}$ in vehicles with and without ABS increased as well and was equal (for different speeds) to $11,5 \%, 18,1 \%$ and $24 \%$, respectively.

2 . Using the values of time $t_{3}, t_{4}, t_{5}$ and the acceleration $a_{x n}$, it was calculated that the average braking distance of a vehicle is less by about $4.26 \%$, as compared to a vehicle without ABS, if the initial speed of movement equals to $40 \mathrm{~km} / \mathrm{h}(10.35 \mathrm{~m}$ and $10.81 \mathrm{~m}$, respectively), and if $v_{0}=80 \mathrm{~km} / \mathrm{h}-$ by about $15.59 \%$ (39.44 m and $33.29 \mathrm{~m}$, respectively). If $v_{0}=60 \mathrm{~km} / \mathrm{h}, S_{T}$ in vehicles with ABS was $20.88 \mathrm{~m}$, and in vehicles without ABS $22.42 \mathrm{~m}$ (the difference - about $7.38 \%$ ). In 
addition, vehicles with ABS are controllable on their emergency braking.

3. The values of the braking distance $S_{T}$ that were calculated on the basis of the earlier found braking parameters, such as the time $t_{3}$ of increase of the deceleration, the settled deceleration $a_{x n}$ and the speed $v_{0}$ of movement before the braking, are scattered in small ranges (upon a certain $v_{0}$ ), so it is proposed to use the found values of the parameters for experts' examination of traffic accidents as well as for closer definition of methods for calculating braking parameters of cars with and without ABS.

\section{References}

1. Council Directive 71/320/EEC of 26 July 1971 on the approximation of the laws of the Member States relating to the braking devices of certain categories of motor vehicles and of their trailers.

2. MITUNEVIČIUS, V. Application of braking responses of vehicles for expert's examinations of vehicles. In Transbaltica-99: Collection of scientific reports of the International Conference (Transbaltica-99: tarptautinès konferencijos moksliniu pranešimu rinkinys, Vilnius, 8-9 April 1999). Vilnius: Technika, 1999, p. 221-226 (in Lithuanian).

3. Vehicles: the manual for students of technical specialties / translated by A. KIRKA (Automobiliai: vadovèlis techninių specialybiu studentams). Kaunas: Tyrai, 2001. 608 p. (in Lithuanian).

4. GILLESPIE, T. D. Fundamentals of vehicle dynamics. Society of Automotive Engineering, Inc. 400 Commonwealth Drive Warrendale, PA 15096-001. 1992. 250 p.

5. ILLARIONOV, V. A. Expert's examination of traffic accidents (Экспертиза дорожно-транспортных происшествий). Moscow: Transport, 1997. 255 p. (in Russian).

6. SOKOLOVSKIJ, E. Investigation on interaction of the wheel with the road and its elements in the context of examination of traffic accidents: Doctor's thesis: technological sciences: Transport engineering (03T). Vilnius, 2004. $147 \mathrm{p}$.

7. KUDARAUSKAS, N. The estimation and analysis of casual factors of car braking parameters. Vilnius, 2005. $80 \mathrm{p}$. 